\title{
Two choice discrimination learning as a function of stimulus similarity along an auditory intensity dimension'
}

JOHN W. MOORE AND JOSEPH HALPERN

UNIVERSITY OF MASSACHUSETTS

\begin{abstract}
Abstraet
One hundred-twenty Ss received 300 trials in a simple auditory discrimination learning situation. Each of two pure tones was associated with one of the alternative choice responses, and the combinations $\mathrm{S}_{1}-\mathrm{A}_{1}$ and $\mathrm{S}_{2}-\mathrm{A}_{2}$ were reinforced $100 \%$ with events $\mathrm{E}_{1}$ and $\mathrm{E}_{2}$, respectively. The two tones differed only in their intensity, and $\Delta \mathrm{I}$ was varied between 0 and $6 \mathrm{db}$. Proportion correct responses was a linear increasing function of $\Delta \mathrm{I}$, and there was no stimulus intensity dynamism effect on response probability.

Problem

The purpose of this experiment was to determine the function relating two-choice discrimination learning to variation of stimulus similarity along an auditory intensity dimension. It was expected that the proportion of correct responses $\mathrm{P}\left(\mathrm{A}_{\mathrm{i}} / \mathrm{S}_{\mathrm{i}}\right)$ would increase as the intensity differential $\Delta I$ between the two stimuli increased. The exact nature of this monotonic function for this situation could not be inferred from earlier research.
\end{abstract}

In an earlier experiment we found that variation of the frequency of pure tones yielded data consistent with the predictions of the linear model of Burke \& Estes (1957). Previous experiments in which stimulus similarity has been manipulated, notably Uhl (1964), have employed matrices of lights to provide discriminable sets of stimulus elements. These experiments have not generally supported the linear model, and Uhl's (1964) experiment in particular was most easily interpreted in terms of Estes' pattern model. The discrepancy between our experiments employing auditory discriminative stimuli and those similar to Uhl's employing light matrices probably lies in an artifact of selective attention which is possible in the latter but not the former.

The present study provides information on the feasibility of employing the intensity dimension in experiments which require fairly precise a priori knowledge of the stimulus similarity parameter of mathematical models. In addition, we wished to make certain that there was no effect of stimulus intensity dynamism on choice-response probability which could complicate experimental designs.

\section{Method}

The Ss were 120 University of Massachusetts undergraduates, distributed randomly into five groups of 24 Ss. The five groups differed in the value of $\Delta I$ which separated the two discriminative stimuli $S_{1}$ and $S_{2}$; the actual intensity pairings in $\mathrm{db}$ SPL were 70-70 $(\Delta I=0)$, 70-68 $(\Delta \mathrm{I}=2), 70-67(\Delta \mathrm{I}=3), 70-66(\Delta \mathrm{I}=4)$, and 70-64 $(\Delta I=6)$. All tones were of $800 \mathrm{cps}$ and were presented together with continuous white noise of $60 \mathrm{db}$ SPL. All auditory stimuli were presented over matched headphones.

Each S was seated before a small Humphreys conditioning board consisting of a 1 in white warning light mounted in the center and 2 in from the top of the panel and two red event lights mounted 4 in above the bottom of the panel and 2 in from either side. Two spring loaded switches were mounted 1 in below each of the event lights. An opaque screen separated adjacent S's.

Each S received a total of 300 trials, 150 trials of each stimulus. Each trial consisted of the presentation of one of the two tones for $2.5 \mathrm{sec}$, a warning light occurring .43 sec. after the onset of the tone, and a reinforcing light occurring $1.5 \mathrm{sec}$. after the onset of the warning signal, its duration being $.57 \mathrm{sec}$. Total time per trial was $2.5 \mathrm{sec}$, and the intertrial interval was a constant $2.5 \mathrm{sec}$.

The sequence of the 300 trials was randomly chosen with the restriction that there be no more than four $\mathrm{S}_{1}-\mathrm{E}_{1}$ or $\mathrm{S}_{2}-\mathrm{E}_{2}$ trials in succession, and two different random sequences were employed. The left-hand response switch and light was designated $A_{1}$ and $E_{1}$ for half of the Ss in each group, and the effect of the position of the more intense stimulus was counterbalanced by designating the right response switch and light $A_{1}$ and $E_{1}$ for the other half of the Ss in each group.

The Ss were instructed to maximize correct responses, and to respond only during the warning signal. No mention was made of the discriminative aspects of the task.

\section{Results and Discussion}

Learning curves showing the proportion of $\mathrm{A}_{1}$ responses to $S_{1}$ and $S_{2}$ for each condition of $\Delta I$ are presented in Fig. 1. It is evident from the figure that clear differences in discrimination performance among the various $\Delta I$ conditions occurred within the first trial-block and were maintained over the remaining trials of the experiments, $F(4,100)=10.27, p<.001$. Closer inspection of Fig. 1 revealed that discrimination performance was a linear function of $\Delta \mathrm{I}$. Leastsquares estimates based on the last trial-block provided the following relationship: 


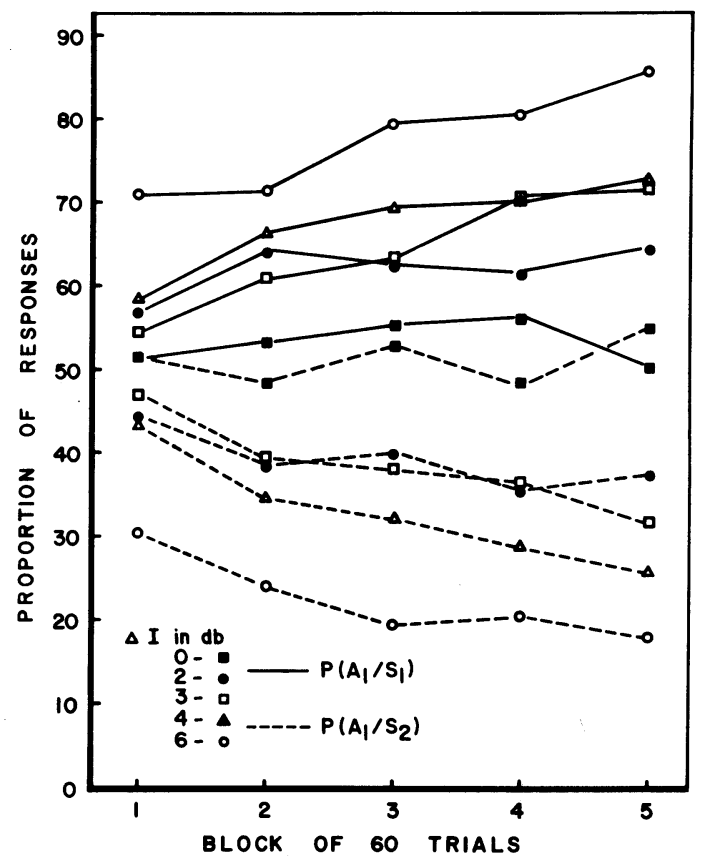

Fig. 1. Proportion of responses in each $\Delta I$ condition as a function of trial-block. For $\Delta I>0$, the more intense tone was arbitrarily designated as $S_{1}$.

$$
\text { Proportion Correct Responses }=.059 \Delta \mathrm{I}+.5
$$

This equation was obtained after group means were shifted by the quantity $2.25 \%$ so as to set percentage correct at exactly $50 \%$ for $\Delta \mathrm{I}=0$.

The same figures used to obtain equation 1 provide the function relating stimulus similarity to $\Delta \mathrm{I}$. The similarity index in question is that given by Burke and Estes (1957) as the parameter $\omega$, namely the ratio of the set-measure of all stimulus elements presented on a trial. In the present experiment, with $\pi$ values of
1 and 0 , and assuming equal set-measure for $S_{1}$ and $\mathrm{S}_{2}$, the relationship between $\omega$ and asymptotic response probability is given by

$$
p=1-\frac{\omega}{2}
$$

From equations 1 and 2 we obtain

$$
\omega=1-.118 \Delta \mathrm{I} \text { 。 }
$$

The inverse of equation 3 will provide experimenters with the proper values of $\Delta I$ for a priori selection of $\omega$ as an independent variable or experimental parameter.

$$
\Delta \mathrm{I}=\frac{1-\omega}{.118}
$$

Thus, a $\Delta \mathrm{I}$ of $4 \mathrm{db}$ at $70 \mathrm{db}$ SPL using $800 \mathrm{cps}$ tones presented over continuous white noise of $60 \mathrm{db}$ SPL would provide a value of $\omega$ approximately equal to .5.

Figure 1 shows that there was no stimulus intensity effects on response choice. In the $\Delta I>0$ conditions, the more intense tone was arbitrarily designated as $S_{1}$. The figure clearly shows that there was no greater tendency to make the appropriate response to $S_{1}$ than to $S_{2}$. This can be seen by the comparative symmetry of the curves about the line $p=.5$. A V-effect would have resulted in an upward shift of all curves.

\section{References}

Burke, C. J., \& Estes, W. K. A component model for stimulus variables in discrimination learning. Psychometrika, 1957, 22, 133-145.

Uhl, C. N. Effect of overlapping cues upon discrimination learning. J. exp. Psychol., 1964, 67, 91-97.

Note

1. This investigation was supported in part by Public Health Service Grant NIH-MH-10794. The authors wish to acknowledge the assistance of Douglas White. 